\title{
M-Learning: The New Horizon of Learning at SQU
}

\author{
Z. Al-Khanjari*, K. Al-Kindi, A. Al-Zidi and Y. Baghdadi \\ Department of Computer Science, College of Science, Sultan Qaboos University, P.O. Box 36, Postal Code 123, \\ Sultanate of Oman
}

Received 11 September 2013; accepted 30 April 2014

\begin{abstract}
M-learning extends the theory and practice of learning and mobility in converging technological environments. Developing a smart course in order to improve the standard of education at Sultan Qaboos University (SQU) is one of the main aims of the current authors. This proposal requires developing innovative applications for ubiquitous, mobile technologies for learning. This kind of development covers new educational and technological methods and concepts for supporting formal and informal learning. SQU is currently using Moodle as the open source e-learning management system to support and enhance traditional learning. Although elearning in SQU has proven its importance in enhancing traditional learning, it is limited to areas and locations where a personal computer exists. This constraint is a burden to many e-learning users who are staff or students, especially if they live in rural areas of Oman. To overcome this drawback, an investigative survey of the importance of m-learning was designed and distributed to SQU students. The results showed that almost all students favored and supported the idea and requested the implementation of a m-learning application. As a step forward, this paper proposes an extension for e-learning-a new m-learning tool to support learners who use mobile device technologies. Our goal in introducing m-learning at SQU is not to replace e-learning but to complement and improve it so both modalities are available, since each grants certain advantages to users.
\end{abstract}

Keywords: Traditional learning, E-learning, M-learning, Mobile application, J2me.

$$
\begin{aligned}
& \text { التعليم الهاتقي: أفق جديد للتعليم هُ جامعة السلطان قابوس } \\
& \text { زهور الخنجرية و خلود الكندية و أسهاء الزيدية و يوسف البغدادي } \\
& \text { الملخص: التعليم باستخدام الهاتف النظرية و التطبيق بهزيد من المعرفة والحركة نحو تقارب البيئات التقنية. } \\
& \text { أظهر الاستطلاع الذي أجري يخ جامعة السلطان قابوس لفحص أهمية التعليم الهاتقي بين الطلبة أن معظم } \\
& \text { الطلبة يفضلون و يؤيدون الفكرة ويطلبون تتفيذها. يخ ضوء مخرجات هذا الاستطلاع تقترح هذه المقالة } \\
& \text { أدوات جديدة للتعليم الهاتفي كامتداد للتعليم الإلكتروني لدعم المتعلمـين الذين يستخدمون هواتف نقالة } \\
& \text { متقدمة. النظام المقترح يهدف لاستكمال منظومة التعليهم الالكتروني وتحسينها ِِّ جامعة السلطان قابوس } \\
& \text { فكل نظام يقدم مزايا مختلفة للمستخدمـين. } \\
& \text { مفاتيح الكلمات: التعليم التقليدي، التعليم الإلكتروني، التعليم الهاتقي، تطبيقات الهاتف،J2m. }
\end{aligned}
$$

*Corresponding author's e-mail: zuhoor@squ.edu.om 


\section{Introduction}

The importance of m-learning emerged because many learning outlets can be provided via mobile devices, which are a part of the daily culture of almost every student and teacher. M-learning, as a new learning technology, is defined as any sort of learning that happens when the learner is not at a fixed, predetermined location, or learning that happens when the learner takes advantage of the learning opportunities offered by mobile technologies (O'Malley et al. 2003). M-learning uses new technologies to develop a simulated student culture and enhance the learning process. It also solves the formality of traditional learning and enhances the selfconfidence and self-esteem of students (Khalaf et al. 2009). Interactive m-learning could be supported by various mobile communication mechanisms such as voice communication access to a learning portal on the internet or learning through short message service (SMS) (Ting 2005).

Enabled by improved software, improved hardware, and evolving habits of mobile device users, the opportunities to develop smart courses have increased even more significantly in past few years. The continuous proliferation of personal smart phones with advanced web browsers has created an incredible opportunity that cannot be ignored. It is now possible to deliver course content across many platforms using mobile browsers. This alternative method has the potential to be more effective and gain wider acceptance by users over computer-based e-learning (Haag 2011). With the smart course, learners would develop critical thinking skills, learning activities and creativity. The aim of the smart course is to improve the quality of learning, training, course organization and student presentation.

This paper presents an ongoing research project which proposes a new m-learning tool for students to resolve e-learning limitations. The study focuses on the student-content learning relationship experimented at SQU with m-learning. It aims to provide anywhere and anytime learning tools for SQU students such that they may reach course content at any time and from any place.
Almost all SQU students possess mobile devices. Indeed, those devices enable students to view teacher announcements or other course material even while on the move. M-learning would also provide a creative environment for students as they enjoy technology's advantages and create a social communication platform between students and their course content.

This research is based on two questions: To what extent does m-Learning at SQU add value to the interactions of students in relation to content and teachers? and How can mlearning complement e-learning at SQU?

To answer these questions, a survey was conducted among SQU students. The survey consisted of five sections: general information, the purpose of using mobile phones, pedagogical aspects, distance learning difficulties and improving learning difficulties.

\section{Related Work}

M-learning started around 2000 when (Sharples 2000) discussed the potential for new designs in personal mobile technologies which could enhance lifelong learning programs. Since then, many educators have indicated positive perceptions about the potential of mobile learning. Articles evaluating mlearning technologies are increasing.

There are many examples of projects which have encouraged the use of m-learning technology and shown its advantages. In 2007, the International Association for Development of the Information Society (IADIS) held the International Conference on Cognition and Exploratory Learning in the Digital Age (CELDA 2007). One paper presented a pilot case study involving learning aspect processes within a m-learning environment: Math4Mobile. Math4Mobile is a cellular application for mathematics learning. The paper discussed Math4Mobile, which could be installed on most cellular phones on the market, as an application designed to support mathematics learning. The researchers watched two pairs of students who studied a mathematics methods course using mobile applications. The case study found that the contribution of the mobile environment not only helped in making dynamic mathematical applications more available, but it also helped 
to support the execution of mathematical tasks that were closer to the students' experiences, which has the potential to enhance experiential learning (Lai et al. 2007; Galit and Michal 2007; Botzer and Yerushalmy 2007).

In another 2007 project, the Higher Education Admission Center in the Sultanate of Oman provided grade 12 students in Omani schools with SMS service to access the center (Khalaf et al. 2009; Al-Mamari 2009). Students sent an SMS from their mobile phones to be able to access and modify their personal information, ask about the offered programs in universities and colleges, register with programs and get final grade results.

In 2008, a new project on Mobile Math (MMATH) commenced. It was a web application designed to run on both mobile devices and personal computers in Malaysian primary schools by using open source technology. MMATH focused on students aged 11 and 12 and facilitated learning mathematics using handheld devices. This m-learning application used a wireless access protocol (WAP) gateway to enable communication between three groups of users: students, teachers and administrators and was designed for two learning environments: web browsers on personal computers and micro browsers on mobile devices.

The computer application was different from the mobile application in that the users of the computer application had to login into the main page. Teachers were able to set questions for quizzes and tests, analyze the student performance in student list and graph view, and post an announcement. The administrator had full privilege to control the system and users of the system. The server side of the system was developed using extensible hypertext markup language (XHTML), wireless markup language (WML), a hypertext preprocessor (PHP) and MySQL, the world's second most widely used open-source relational database management system. By including the uniform resource locator (URL) dialing function in the implementation, the student was able to call his teacher. A JpGraph module (Asial Corp, Tokyo, Japan) was used to implement the graph generating functionality. The application provided a progress tracking function that allows users to view their progress and student performance from time to time. Also, there was an announcement function, which allowed teachers to post any news or update about the course. The user tests showed a significant improvement in terms of student satisfaction with and performance for the m-learning environment compared to a more traditional learning approach (Saipunidzam et al. 2008; Saipunidzam et al. 2010).

MyArtSpace, another m-learning project, engaged students through personal mobile technology to make connections between learning within the classroom and the outside environment (Vavoula et al. 2009).

In 2010, the Department of Computer Science at the University of Alcala in Spain introduced a new mobile application designed for auto-assessment that allowed students to test their knowledge and expertise on a specific topic using questionnaires designed by their teachers. The system was developed using Java technology and Java Micro Edition (JME) for the mobile application (Oracle Corp., Redwood City, California, USA) and extensible style sheet language transformation (XSLT) sheets. The system consisted of three subsystems: a web server to store, deliver and evaluate online tests; a mobile application that students employ to connect to the server, download questionnaires and complete them; and a webbased from-end that is used to offer different functionalities to each kind of user (students, teachers and administrators) (Luis et. al. 2010; de-Marcos et al. 2010).

Existing programs that leverage mobile course delivery as part of their overall training strategy have been in existence in the corporate sector for several years. Few studies have been conducted on the general effectiveness of this specific form of delivery in a military setting (Haag 2011).

In another study, $\mathrm{Wu}$ and colleagues mentioned that mobile phones and personal digital assistants (PDAs) are the most commonly used devices for m-learning but they may be replaced in the future by new emerging technologies (Wu et al. 2012). Also, Trucano, who is the World Bank's Senior Information and Communication Technology (ICT) and Education Policy Specialist, serves as the World Bank's focal point within the education sector on issues at the intersection of technology use and education. He talked about the World Bank's infoDev project. The World Bank secured funding to do a global survey of 
the use of mobile phones in education in developing countries based on the belief that the increasing availability of the small, connected computing devices more commonly known as "mobile phones" was going to have

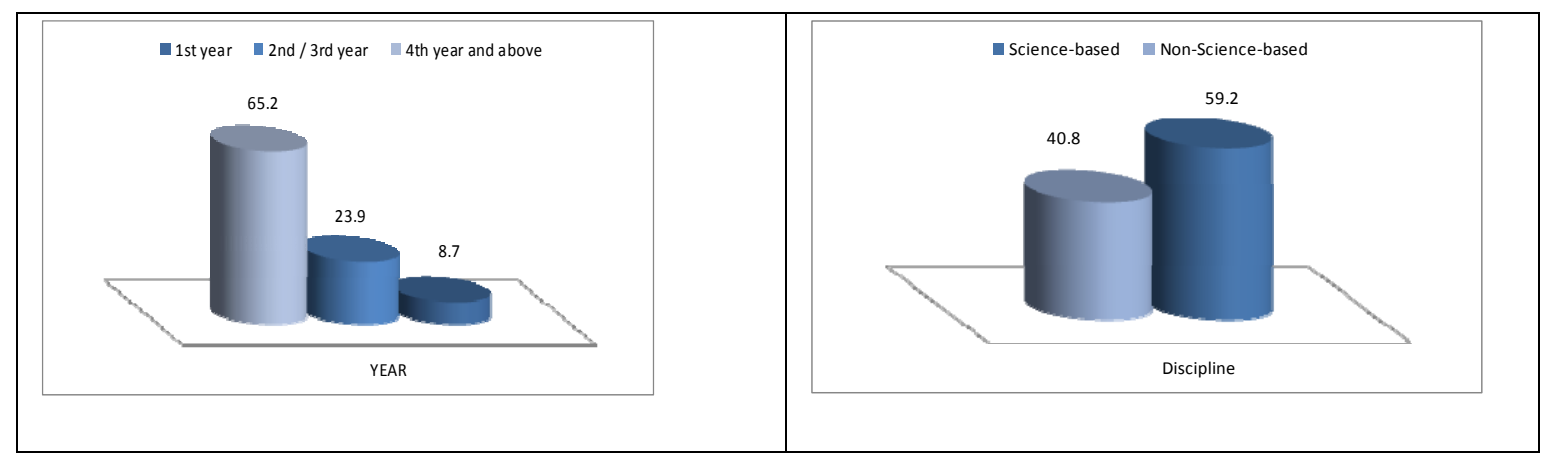

Figure 1. e-Learning Usage in SQU.

Figure 1 shows that the final years and science-based students are more adopted to computers. Therefore, it became obvious that they use the e-Learning facilities more than others.

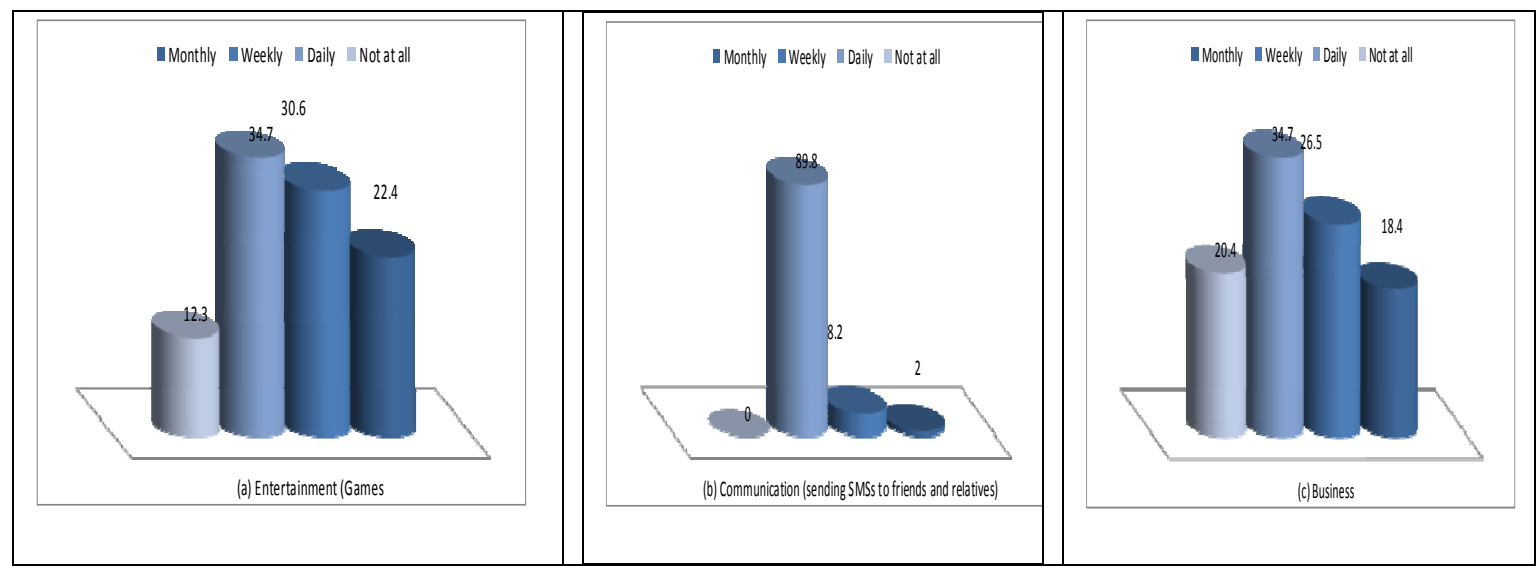

Figure 2. Mobile Phone Usage.

Figure 2 Displays that Most Students use their Mobile Phones Daily in their Entertainment, Communication and Business.

increasing relevance to school systems around the world (Trucano 2012).

Recently, Gluga and colleagues contributed to finding foundations for mobile university curricula in terms of multiple learning goal sets (Gluga et al. 2013).

\section{Development of SQU M-Learning Application Tools}

Students at SQU use and support e-learning in their studies. Although this is the case, they do not complain about the lack of available elearning resources when they are away from campus. This lack of e-learning opportunities cannot help them to achieve their educational objectives. This section first checks the importance of introducing a m-learning application tool. Then it provides the design of such tool. Finally, it shows the implementation of the m-learning tool.

\subsection{The Importance of Introducing a M- Learning Application Tool}

Due to the lack of e-learning facilities that can reach all users in all areas of the Sultanate of Oman, a questionnaire was distributed to SQU students from all colleges. The aim of this survey was to show the potential significance of introducing new m-learning services in SQU in order to improve the existing e-learning facilities. Results of the survey are demonstrated in Figs. 1 and 2. 


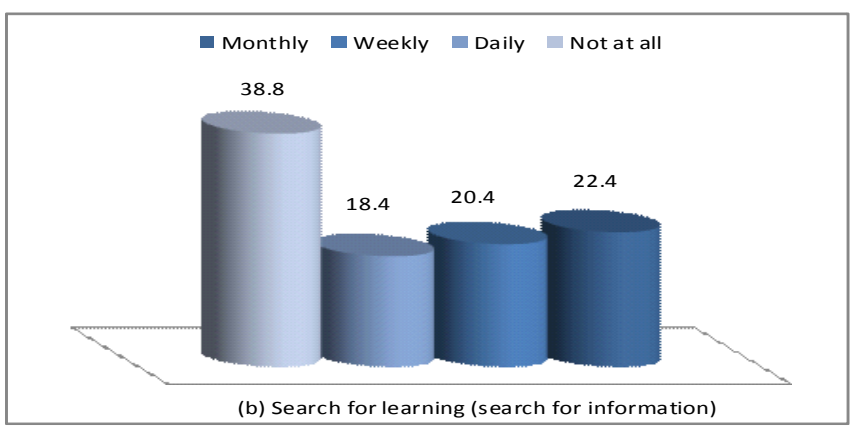

Figure 3. Frequent of using Mobile Phones for Study Purposes.

Figure 3 shows that most of the students would like to use their smart phones for education purposes. But unfortunately, they aren't able to do so because of the lack of m-Learning applications in SQU. The study showed that establishment of such application is very important for the students to overcome the limitations of e-Learning.

\subsection{Design of the M-Learning Application Tool}

The Design of the m-Learning application tool is described with the Use Case Diagram illustrated in Fig. 4. The application is divided into two separate subsystems: a) Interface program for teacher, and b) Interface application for student. Teacher/instructor is able to login, add study material, upload assignment, post grades and post announcement. On the other hand, the student

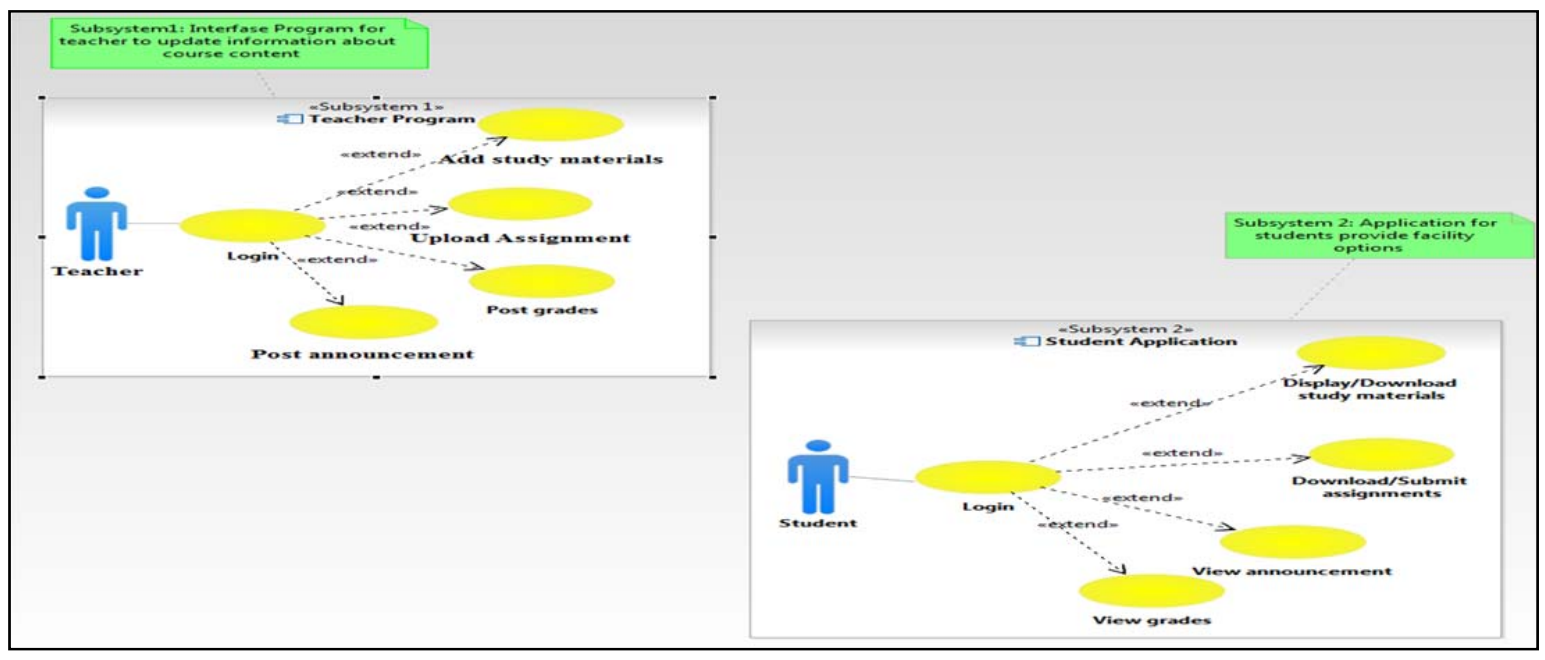

Figure 4. Use Case Diagram of the M-Learning Application Tool.

is able to login, display/download study material, download/submit assignments, view announcement and view grades.

\subsection{Implementation of the M-Learning Application Tool}

Implementation is the part of the process where software engineers actually program the code for the project. Also, the implementation phase provides the conceptual foundation required for the design and development of complex distributed and real-time applications.

The tool is implemented using Visual Basic language in Microsoft Visual Studio 2010 environment, Java2 Micro Edition in NetBeans IDE 9.6.1 environment and SQL server 2008 R2. These facilities enable us to design the interface and implement the code easily.

Figure 5 provides the architectural design of m-Learning application tool with the two 


\section{Z. Al-Khanjari, K. Al-Kindi, A. Al-Zidi and Y. Baghdadi}

implemented interfaces for both subsystems mentioned in the Use Case diagrams. First, the student has to login via the main page mobile application interface by entering his/her username and password. As a result, valid login case menu screen will be displayed. The student will then be able to select any of the offered choices.

Mobile application interface for students is designed using J2ME However, the teacher's interface is developed using Visual Basic programming language.

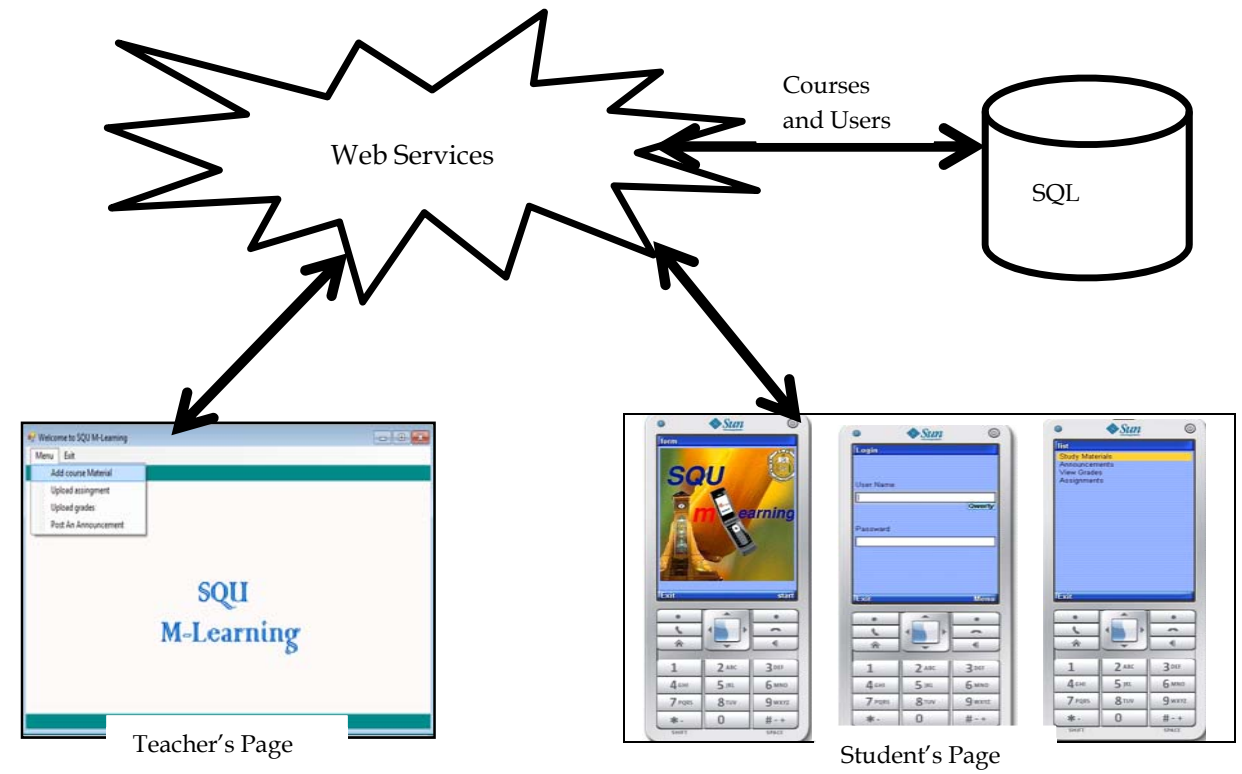

Figure 5. The Architectural View of the SQU M-Learning Application.

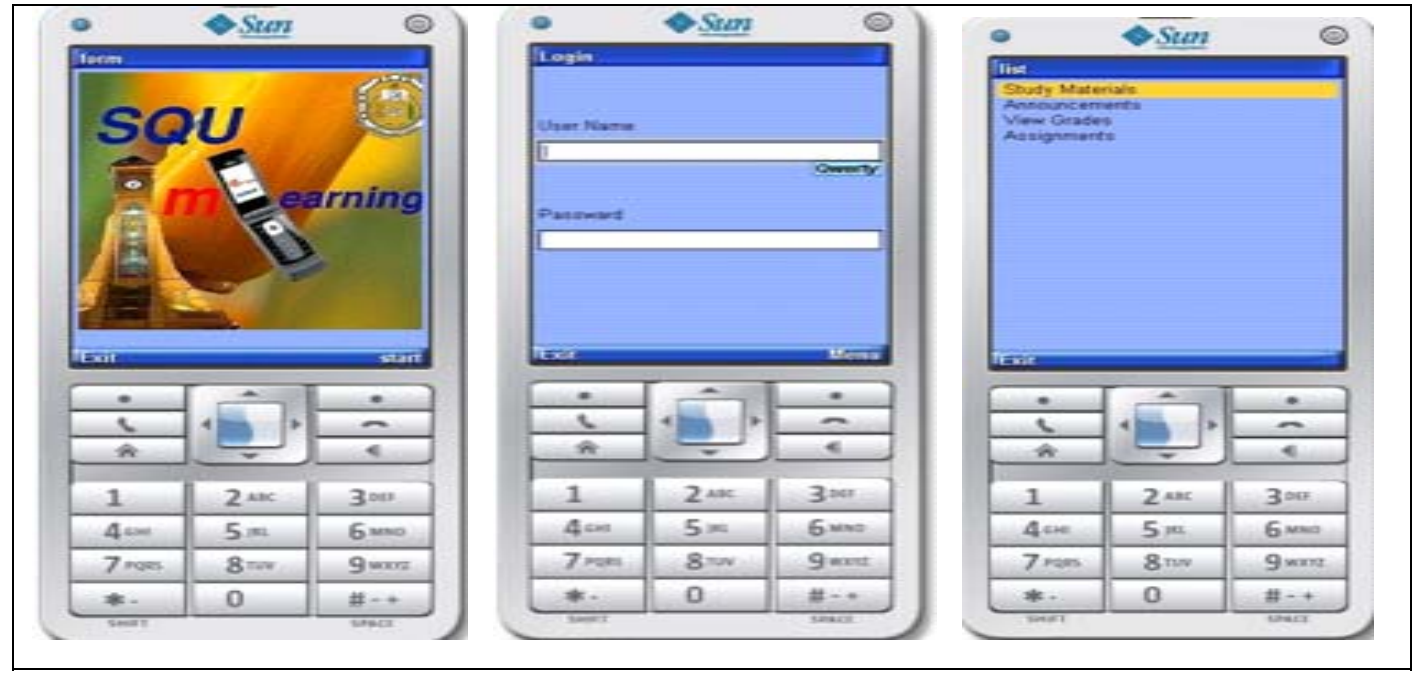

Figure 6. An Application on Student's Mobile Phones as Client Side.

Mobile application interface for students is designed using J2ME (Java for mobile application) (Enrique Ortiz and Giguere, 2001). However, the teacher's interface is developed using Visual Basic programming language.

ASP.NET is used to create the web service, which is connected to oracle SQL database.
This connection is important to store announcements, study materials, quizzes, assignments and grades added by the teacher in the database. The web service then gets these required data by connecting to the same database to transform them to the application in students smart phones. 
The proposed tool comprises the following four different parts to form the complete system. They are explained further in the following sections.

- An application on mobile phone as client (eg. student) side.

- An application on teacher personal computer.
- A web service connected to both applications.

- SQL database for storing and retrieving information about students and courses.

\subsubsection{Student Interface}

Students can download and save available study materials, announcements, assignments and grades while connecting to

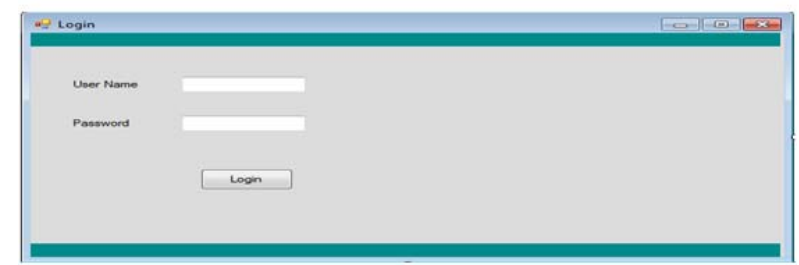

Figure 7. The Login Screen of the Teacher.

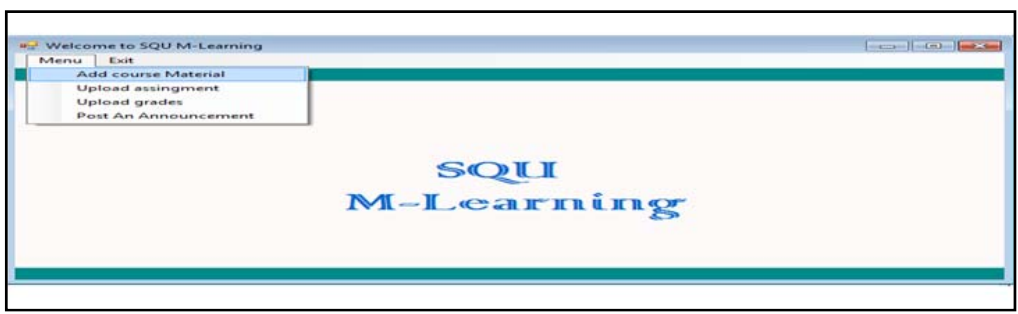

Figure 8. Menu Screen for the Teacher.

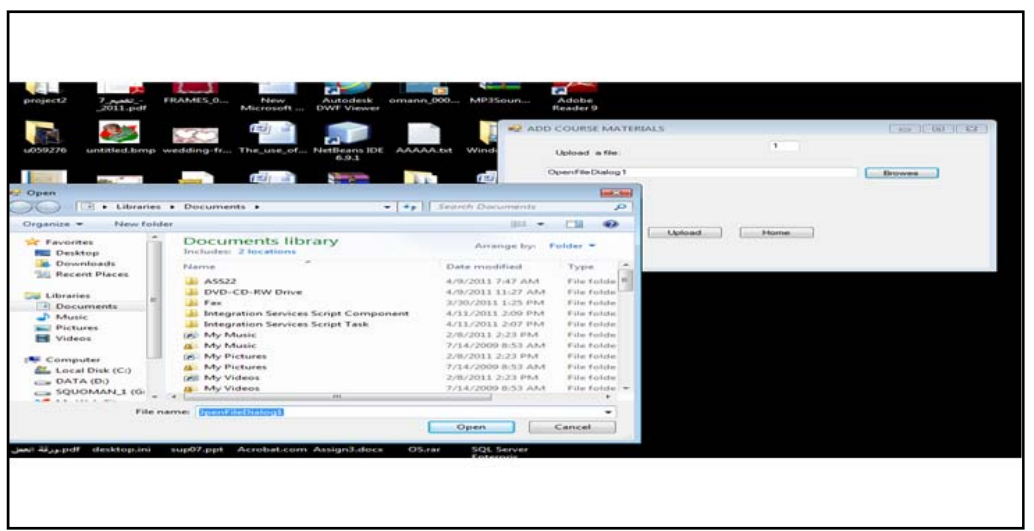

Figure 9. Open File Dialog when Teacher Clicks on "Browse" Button.

the internet. They can disconnect from internet after completing the download to view announcements and grades or print course materials and assignments. Figure 6 shows some of the application screens in the students mobile phones (Al-Zeidi et al. 2011).

\subsubsection{Teacher Interface}

Teachers can prepare/upload course materials, store announcement and prepare/manage quizzes, assignments and grades.

Figure 7, shows the first form (eg. Login form), which appears once the application program runs. This form includes two textboxes for entry of teacher username and 
password. To login to the tool and establish connection to the database, the teacher should provide his/her username and password, which should be followed by clicking on the "Login" button. The tool then checks the validation of the teacher entries. If the program failed to connect with database then an error message should appear. Otherwise, if the program didn't find a match of the username, password or both in the teachers'

data table, a message should appear requesting the teacher to reenter valid entries to be able to go to the next window. If the teacher entries are valid, a menu window appears and the teacher can select the wanted choice as shown in Fig. 8.

For each choice, a related window is displayed. For example, if the teacher clicks on "Add Course Material" then the Add Course Material window is displayed as shown in Fig. 9.

In order to upload the course material, the teacher should click on the "Browse" button shown in Fig. 9. As a result, Open window is displayed through which the required files could be uploaded. This window is also displayed in Fig. 9. Teacher then selects the file and clicks on "Upload" button to store the file in the database.

\subsubsection{Web Service}

In visual basic environment we implemented a web service using ASP.NET. The web service written in VB language and has four functions. The function in ASP.NET is declared as Web Method() so that before any function declaration the statement $<$ WebMethod() > is included.

To connect to the required database in the SQL Server we imported in the following libraries as indicated in the Fig. 10 below.

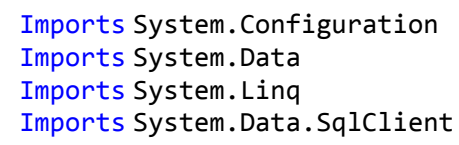

Figure 10. Code of Connecting ASP.Net to SQL Server

The code of connecting ASP.NET to SQL Server is similar to that used in connecting VB to SQL Server. In the following code, we connected to a local database. The following figure shows an example the data from table "tableName".

\subsubsection{J2ME Implementation}

In the environment of J2ME we dragged the item we wanted to appear in the phone screen from the list of items. This is when we choose the tap screen. There is another tap which is "Flow" which enabled us to make the relationship and connect channels between different screens. The code is written by clicking on "Source" tap. The following figure is of our flow.

To connect J2ME to the web service we can use one of the following two ways:

- Implement connection using ksoap.

- The second way is to use Get Http as shown in the following figure.

\subsubsection{SQL Server Implementation}

Creation of the database is very direct in SQL server. Also, the table and columns creation were done quickly without needing to write any code. We created quires by clicking on "New Query" tab and used them for altering tables and adding primary and foreign keys. After creating the database and tables we inserted values in ID and Password columns in both student and teacher tables. We also inserted values for Cid (course id) and Cdesc (course description).

Figures 16, 17, 18 and 19 provide the details about tables and columns and examples of used queries.

\section{Conclusions}

Mobile technologies can play an important role in SQU students' academic lives. Mobile devices connect users to the world instantly, heightening access to information and enabling interactivity with others. Applications such as m-courses that run on these devices let users not only consume but also discover and produce content. This can enhance the students learning and influence their learning preferences, both within and outside the classroom.

To successfully adopt mobile technologies across the university, this paper presented the 
ongoing research work in developing mobile learning services for SQU students. It discussed the needs for m-Learning for achieving several goals, which could lead to a great success in learning process in our country. Students in SQU have heard about mobile learning technology and they are waiting for the time to be able to enjoy its benefits and facilities.
For the future work, teachers' interface could be enhanced by preparing it as a web page using VB.NET. Also, the tool could be improved by using SMS facility to send messages to students whenever a new material is posted on the site of the smart course. On the other hand, instructors could be informed via SMS when any assignment or project is submitted by the student.

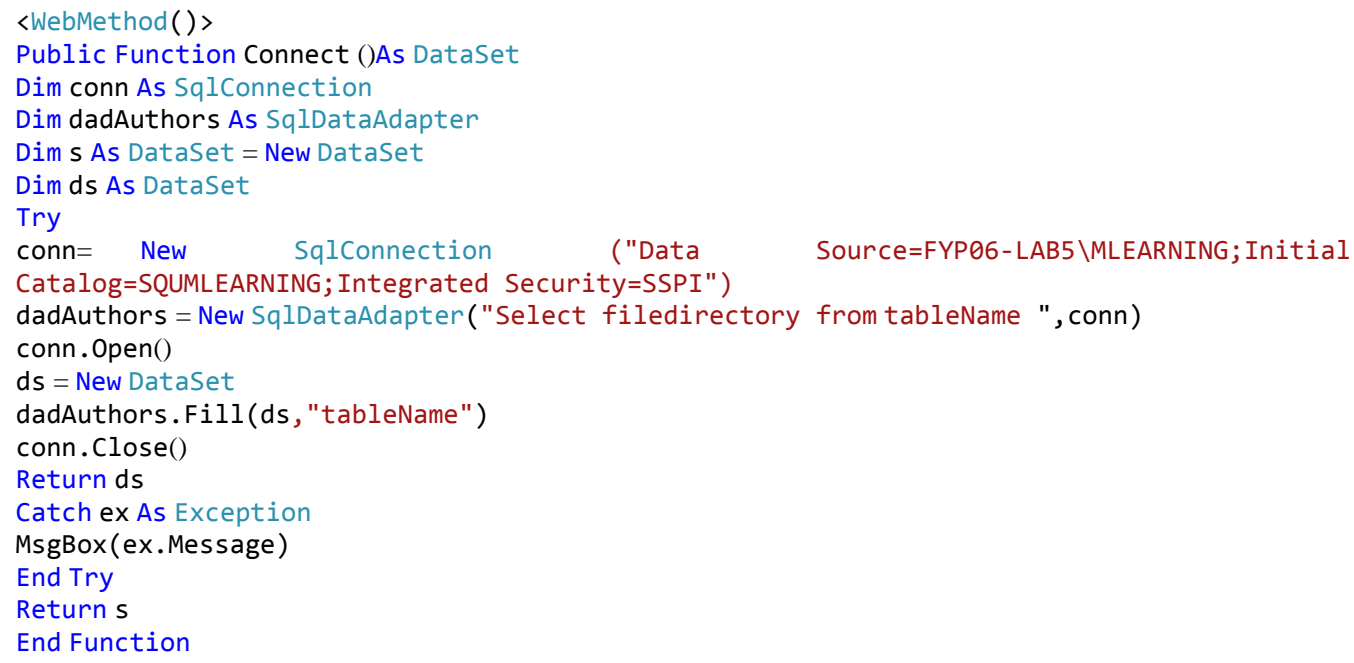

Figure 11. Web Method in ASP.Net.

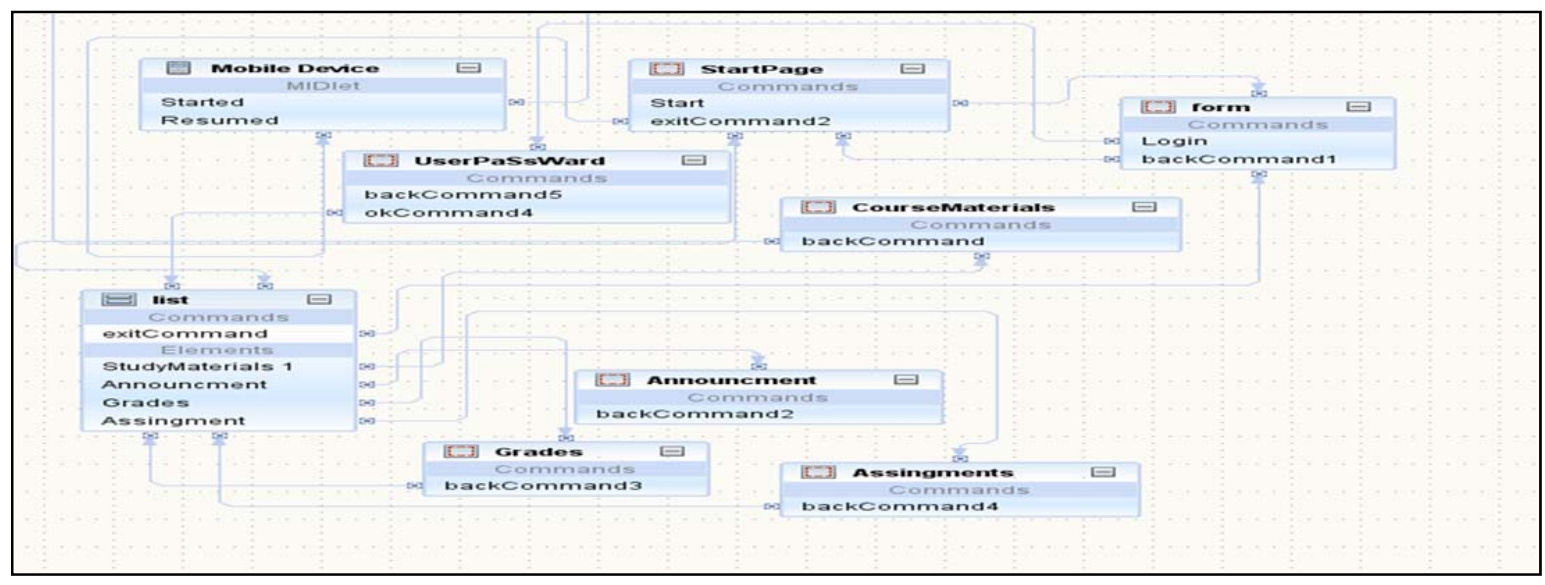

Figure 12. Flow of J2ME Application.

import org.ksoap.*;

import org.ksoap.transport.*;

import org.ksoap.SoapObject;

Figure 13. Code of Import ksoap. 
Figure 14 shows the entire code of adding the URL to connect with and store data in string buffer.

public void doWebService(String url) throws Exception

\{

StringBuffer $\mathrm{sb}=$ new StringBuffer();

String name = "Phobos";

TextBox textBox = null;

SoapObject client $=$ new SoapObject(url, "sayHello");

client.addProperty("name", name);

HttpTransport ht = new HttpTransport(url,

Figure 14. Code of Connect to URL.

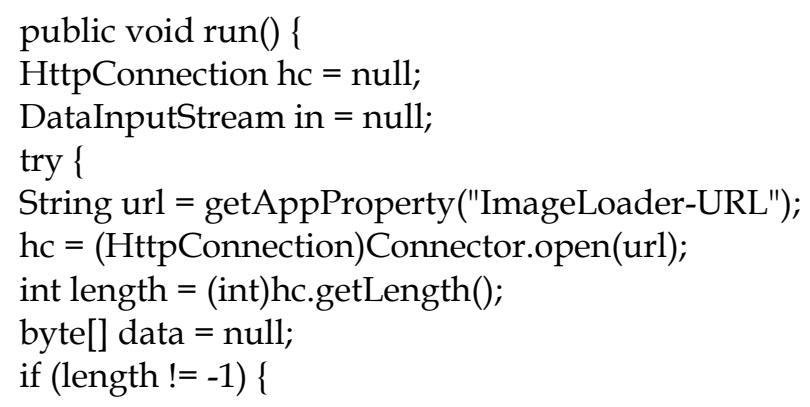

Figure 15. Code of Connect to URL using Get Http.

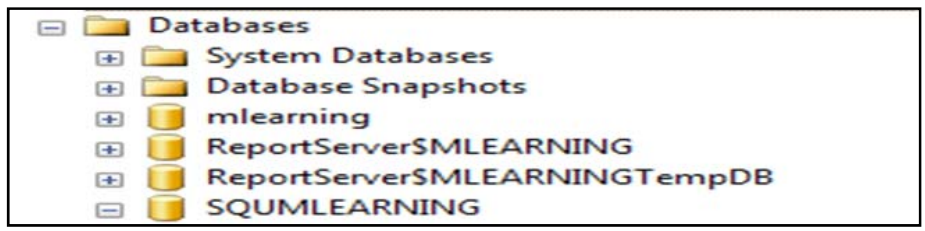

Figure 16. Databases list in SQL Server.

\begin{tabular}{|l|}
\hline$\square$ Tables \\
System Tables \\
dbo.Course \\
Columns \\
C CID (PK, nchar(2), not nuII) \\
CDesc (varchar(10), nuII) \\
SM (nvarchar(max), nuII) \\
Ass (nvarchar(max), nuII) \\
Grade (nvarchar(max), nuII) \\
Ann (nvarchar(max), nuII)
\end{tabular}

Figure 17. Course Table and its Column Specifications.

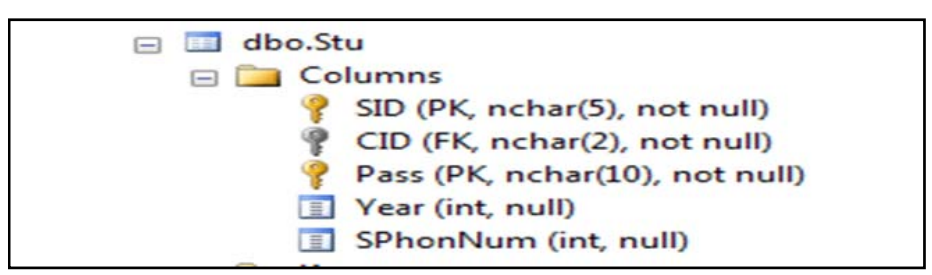

Figure 18. Student Table and its Column Specifications. 


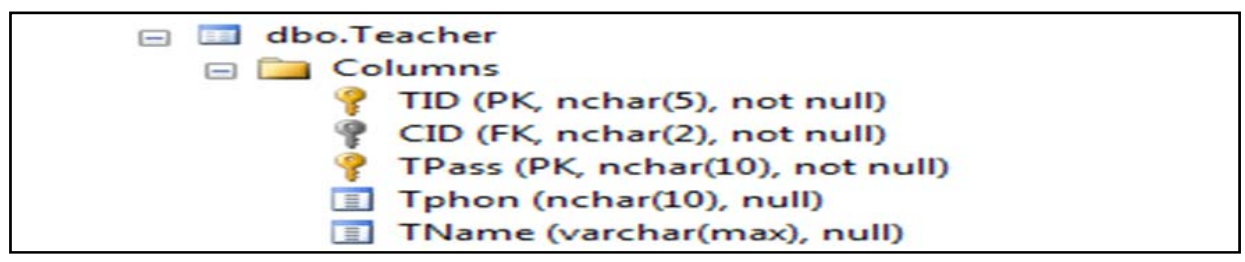

Figure 19. Teacher Table and its Column Specifications.

\section{References}

Al-Mamari KS (2009), The Effect of mobile learning technologies on students' listening skills in higher education in the Sultanate of Oman. Thesis for the degree of Master in Education. Department of Curriculum and Instruction. College of Education. Sultan Qaboos University, Oman.

Al-Zeidi A, Al-Kindi K, Al-Khanjari Z (2011), SQU future: from E-Learning to M-Learning application development. The Proceedings of The International Information Systems Conference (iiSC). College of Commerce, Sultan Qaboos University, Oman.

Botzer G, Yerushalmy M (2007), Mobile application for mobile learning. IADIS International Conference on Cognition and Exploratory Learning in Digital Age (CELDA 2007):313-316.

de-Marcos L, José-Ramón H, Eva G, Antonio G, José-Javier M, José-María G, Roberto B, Salvador O, José-Antonio G, Elena V, Miriam M, Salvador E (2010), A mobile learning tool to deliver online questionnaires. Computer Science Department, University of Alcalá, Spain: 319-320.

Enrique OC, Giguere E (2001), J2ME: The complete reference. John Wiley \& Sons, USA.

Galit B, Michal Y (2007), "Mobile application for mobile learning. The International Conference on Cognition and Exploratory Learning in Digital Age (CELDA 2007): 313-316.

Gluga R, Kay J, Lever T (2013), Foundations for mobile University curricula in terms of multiple learning goal sets. IEEE Transactions on Learning Technologies 6(1).

Jason H (2011), From eLearning to mLearning: The effectiveness of mobile course delivery. Interservice/Industry Training, Simulation, and Education Conference (I/ITSEC).
Khalaf R, Mukhi N, Weerawarana S (2009), A pervasive distributed architecture for $\mathrm{m}$ Learning is presented based. Journal of Mobile Learning and Organization 3(2):128-147.

Lai CH, Yang JC, Chen FC, Ho CW, Chan TW (2007), Affordances of mobile technologies for experiential learning: the interplay of technology and pedagogical practices. Journal of Computer Assisted Learning, 23(4):326-337.

Luis JRH, Eva G, Antonio G, José-Javier M, José-María G, Roberto B, Salvador O, JoséAntonio G, Elena V, Miriam M, Salvador E (2010), A mobile learning tool to deliver online questionnaires. Department of Computer Science, University of Alcalá, Spain 319-320.

O'Malley C, Vavoula G, Glew J, Taylor J, Sharples M, Lefrere P (2003), MOBIlearn WP 4 - Guidelines for Learning/Teaching /Tutoring in a Mobile Environment. MOBIlearn / UoN,UoB,OU / D4.1/1.0.

Parsons D, Ryu H, Cranshaw M (2007), A design requirements framework for mobile learning environments. The Journal of Computers. 2(4):

Saipunidzam M, Mohammad N, Mohamad I, Shakirah M (2008), Open source implementation of M-Learning for primary school in malaysia. International Journal of Human and Social Sciences 3(4):309-313.

Saipunidzam M, Mohammad N, Mohamad I, Shakirah M (2010), M-Learning: A new paradigm of learning mathematics in Malaysia. International journal of computer science \& information Technology (IJCSIT), 2(4):76-86. 
Sharples M (2000), The design of personal mobile technologies for lifelong learning. Computers and Education 34:177-193.

Ting YL (2005), Mobile learning-current trend and future challenges. Proceedings of the fifth IEEE ICALT'05.

Trucano M (2012), Mobile learning and textbooks of the future, e-reading and edtech policies: Trends in technology use in education in developing countries. World Bank's EduTech blog, 4.
Vavoula G, Sharples M, Rudman P, Meek J, Lonsdale P (2009), Myartspace: design and evaluation of support for learning with multimedia phones between classrooms and museums. Computers $\mathcal{E}$ Education, DOI: 0.1016/j.compedu.2009.02.007.

Wu W, Wu Y, Chen C, Kao H, Lin C, Huang S (2012), Review of trends from mobile learning studies: A meta-analysis. Computers $\mathcal{E}$ Education 59(2):817-827. 